Original Article

\title{
VALIDATION METRICS OF THE MASTOID TRIANGLE
}

\author{
Bhagya B. ${ }^{1}$, Hema N. ${ }^{1}$ \& Ramakrishna A. ${ }^{2}$ \\ ${ }^{1}$ Lecturers, ${ }^{2}$ Professor, Department of Anatomy, Yenepoya M edical College, \\ Yenepoya University, Deralakatte, M angalore 575018, Karnataka, India \\ Correspondence: \\ Ramakrishna Avadhani \\ Professor \& HOD, Department of Anatomy, Yenepoya M edical College, Yenepoya University \\ Deralakatte, University Road, M angalore - 575018. \\ Phone: +91 824220 4668/69/70, M obile : +91 9845905220, Fax: +91 8242204667 \\ E-mail : drrka99@gmail.com
}

\begin{abstract}
:
The purpose of this study was to validate the technique developed by Paiva and Segre for sex identification using the mastoid process. Total mastoid area is calculated by adding the right and left triangular areas defined by three distinct craniometric points: the Asterion, Porion and the Mastoidale. Eight skulls ( 40 males and 40 females) were analysed and total area calculated using Heron's formula. The mean total area of the male skulls is higher compared to females $\left(1461.06 \mathrm{~mm}^{2} \mathrm{vs} 1222.79 \mathrm{~mm}^{2}\right)$. Independent t-tests reveal that there are significant differences between males and females, with p-values less than 0.0001 .
\end{abstract}

Keywords: M astoid process, Mastoid triangle, sexual dimorphism, metrics

\section{Introduction:}

The mastoid process is a pyramidal shaped posterior projection of the temporal bone located on each side of the head behind the ear. It is situated just behind the auditory meatus, and lateral to the styloid process. The mastoid bone forms the attachment area for many muscles which is the reason for the process to be more robust in males due to larger muscles compared to females. ${ }^{1}$ The mastoid process has been studied by various researchers in different populations for sexual dimorphism. ${ }^{1-6} A$ technique reported by Paiva $\&$ Segre $^{2}$ for sex differentiation in the mastoid process is made by calculating the total area of the mastoid triangle. The technique involves measuring the distance between three triangular points (Porion, Mastoidale and Asterion), calculating the area of this triangle, adding the left $\&$ right mastoid triangle areas of the skull which gives the Access this article online Quick Response Code

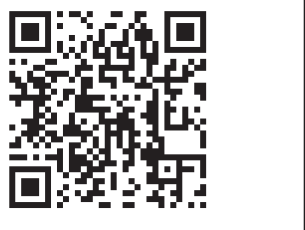
total area used to identify sex. If the value of the total area is greater or equal to $1447.40 \mathrm{~m} \mathrm{~m}^{2}$, it represents a male skull, and values less than or equal to $1260.36 \mathrm{~mm}^{2}$ indicates a female skull ( $95 \%$ confidence). Total area is used for the study due to asymmetry of the mastoid process between the skulls. Unequal mastoid process is formed due to pneumatisation (air-filled cavity) and the size of the mastoid air cell system is determined by the degree of pathological involvement of the middle ear during childhood. ${ }^{3}$

\section{Materials \& methods:}

The study sample was taken from the Department of Anatomy, Yenepoya Medical College, Yenepoya University, Mangalore, Karnataka, India, which represents the South Indian Population. The skulls which presented trauma or deformations were excluded from the study. A total of 80 skulls ( 40 male and 40 female) aged between 35 to 60 years in department record book were selected for the study. Three points forming the landmarks of the mastoid triangle were located and marked by a single investigator (HU) on both sides of the skull. The dimensions of the mastoid triangle are formed between Porion (Po - superior point of the external auditory meatus), M astoidale (M s - lower tip of the mastoid process) and Asterion (As - the meeting point of the lambdoid, occipitomastoid and parietomastoid sutures) (Fig 1). The linear measurements between the points were made using a vernier calliper 
$(0.01 \mathrm{~mm})$. The mastoid triangle area was calculated using Heron's formula: with sides of triangle $a, b \& c$.

$$
A=\sqrt{(s(s-a)(s-b)(s-c))} \quad \text { and } s=\frac{(a+b+c)}{2}
$$

\section{Statistics:}

Using SPSS Win 13 program descriptive statistics of the linear dimensions of the mastoid triangle area was calculated; the significance of the mean differences in relation to sexwascalculated usingt-test $(p \varangle 0.05)$.

\section{Results:}

The values of right, left and total mastoid triangle area of both male and female are presented in Table 1. Descriptive statistics reveal clear differentiation between male and female mastoid processes. In the 80 skulls analyzed, all the lineal dimensions of the mastoid triangle and the calculated areas were higher in males than in females (Table 1). The mean total area of the male skulls is higher compared to females (1461.06 $\mathrm{mm}^{2}$ vs $1222.79 \mathrm{~mm}^{2}$ ). Independent t-tests reveal that there are significant differences between males and females, with $p$-values less than 0.0001 .

\section{Discussion:}

The mastoid region is considered as the most protected and resistant to damage, due to its anatomical position at the base of the skull. ${ }^{4}$ The qualitative assessment of the mastoid process has been widely used to estimate the sex of an individual due to characteristics such as their size, ruggedness for muscular inserts, or mastoid process inclination are very good indicators of sexual dimorphism. ${ }^{5}$ In the present study quantitative assessment of the mastoid triangle total area is used for sex prediction. The results of our study support the technique developed by Paiva \& Segre ${ }^{2}$ which is an easy and quick method for sexing skulls. One of the limitations of this technique is its use in sexing individual skulls ${ }^{6}$, and also due to asterion point localization, which position changes during the course of life. $^{7}$

Acknowledgement: The authors are grateful to Yenepoya University for permission to carry out this study at the Department of Anatomy.
Table 1: Descriptive statistics of the mastoid triangle $\left(\mathrm{mm}^{2}\right)(\mathrm{n}=40 ;$ mean \pm SD)

\begin{tabular}{|l|c|c|c|}
\hline Sex & \multicolumn{2}{|c|}{ Mean } & Total area \\
\hline & Right area & Left area & \\
\hline M ale & $726.76 \pm 58.12^{\mathrm{a}}$ & $734.3 \pm 57.3^{\mathrm{a}}$ & $1461.06 \pm 115.29^{\mathrm{a}}$ \\
\hline Female & $607.63 \pm 78.10^{\mathrm{b}}$ & $615.16 \pm 77.82^{\mathrm{b}}$ & $1222.79 \pm 155.82^{\mathrm{b}}$ \\
\hline
\end{tabular}

Figures across the rows with different letters are significantly different $(p<0.0001$, paired t-test)

Figure 1: Lateral view of the cranium depicting the landmark points: Porion (Po), Asterion (As) and M astoidale (Ms) forming the mastoid triangle.

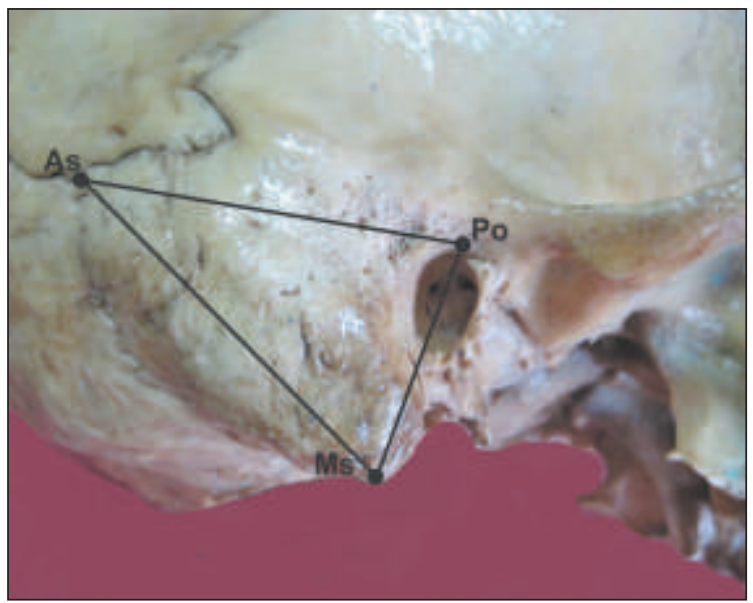

\section{References:}

1. Bernard K A, M oore-Jansen P H. Quantifying male and female shape variation in the mastoid region of the temporal bone.

2. De Paiva $L A$, Segre M. Sexing the human skull through the mastoid process. Rev Hosp Clin Fac M ed São Paulo. 2003; 58(1): 15-20.

3. Tos M, Stangerup SE. The causes of asymmetry of the mastoid air cell system. Acta Oto- Laryngologica. 1985; 99:564-570.

4. Kalmey J K, Rathbun T A. Sex determination by discriminant function analysis of the petrous portion of the temporal bone. Journal of Forensic Science. 1996; 41: 865-867.

5. Suazo G I C, Zavando M D A, Smith R L. Sex determination using mastoid process measurements in Brazilian skulls. International Journal of M orphology 2008; 26(4):941-944.

6. Kemkes A, Gobel T. M etric assessment of the "mastoid triangle" for sex determination: a validation study. Journal of Forensic Science. 2006; 51: 985-989.

7. Day J D, Tschabitscher M. Anatomic position of the asterion. Neurosurgery. 1998; 42: 198-199. 